American J. of Engineering and Applied Sciences 2 (4): 580-583, 2009

ISSN 1941-7020

(C) 2009 Science Publications

\title{
Synthesis and Characterization of Hot-Roll and Cold-Roll Byproduct-Derived Strontium Hard Ferrites
}

\author{
${ }^{1}$ H.S. Woon, ${ }^{2}$ K.P. Lim, ${ }^{1}$ N. Puteri, ${ }^{1}$ R. Rozaimah and ${ }^{1}$ C.Y. Tan \\ ${ }^{1}$ Department of Engineering Science and Mathematics, College of Engineering, \\ University Tenaga National, KM 7, Jalan Kajang-Puchong, \\ 43009 Kajang, Selangor, Malaysia \\ ${ }^{2}$ Department of Physics, Faculty of Science, University Putra Malaysia, \\ Serdang 43400, Selangor, Malaysia
}

\begin{abstract}
Problem statement: Ceramic permanent magnets or more commonly known as strontium hexagonal ferrites have been widely used in permanent magnetic materials as they provide high remanence, high coercivity, relatively high energy product and good chemical stability. In this study, we treated factory byproduct from hot-roll and cold-roll steel industry was used as raw material in synthesis of strontium hexagonal hard ferrites. Approach: X-Ray Diffraction (XRD) was employed to confirm the formation of strontium hard ferrite compound. Vibrating Sample Magnetometer (VSM) was used to analyze the magnetic properties of samples prepared. Results: The magnetic properties, namely remanence and coercivity of factory byproduct-derived strontium hard ferrites were compared. The cold-roll-derived strontium hard ferrite showed higher remanence in this study. Conclusion: This implied that cold-roll byproduct was a better candidate to replace hematite in preparation of strontium hard ferrites compared to hot-roll byproduct.
\end{abstract}

Key words: Strontium hard ferrites, remanence, coercivity, hot-roll steel industry, cold-roll steel industry

\section{INTRODUCTION}

In the steel-making industry, hot rolling process consists of slab-heating (as well as billet and bloom), rolling and forming operations. Several types of hot forming mills (primary, section, flat, pipe and tube, wire, rebar and profile) manufacture diverse steel products. Long products are manufactured by hot rolling billets into reinforcement bars, or for further rolling and drawing into wire rods and sometimes coating. To prepare the steel for cold rolling or drawing, acid pickling (inorganic acid water solutions with sulfuric or hydrochloric acid) is performed to chemically remove oxides and scale from the surface of the steel. Other methods to remove scale include salt pickling and electrolytic pickling. Cold rolling follows hot rolling operations, for the manufacture of a thin strip or a strip with a high-quality finish ${ }^{[1]}$. The surface of hot rolled steel is covered by a layer of mill scale which is created by a reaction of the metal and ambient oxygen while the hot rolled steel is cooling down. The layer of scale consists of three different types of iron oxide $\mathrm{FeO}, \mathrm{Fe}_{3} \mathrm{O}_{4}$ and $\mathrm{Fe}_{2} \mathrm{O}_{3}$. Rolling mill scale is considered a rich iron source $(>70 \% \mathrm{Fe})$ with minimum impurities.

In continuous pickling processes, the steel is immersed in acid cleaning tanks (containing hydrochloric, sulfuric, or a combination of various pickling acids) and then cleaned in a series of water rinsing tanks. Some by-products in spent pickling liquor include iron-bearing materials that could be used in the production of magnetic powder products $^{[2]}$. Pickling acid regeneration sludge can be recycled in steel plants (EAF and blast furnace) or processed for the production of iron oxides. The iron oxide from hydrochloride acid regeneration can be used in several industries as a high quality input such as for production of ferromagnetic materials, iron powder, or construction material, pigments, glass and ceramics $^{[1]}$.

In this study, factory byproduct from hot-roll and cold-roll steel industry undergo a series of treatment; milling, magnetic separation and heat treatment, to be

Corresponding Author: H.S. Woon, Department of Engineering Science and Mathematics, College of Engineering,

University Tenaga National, KM 7, Jalan Kajang-Puchong, 43009 Kajang, Selangor, Malaysia 
converted into hematite $\left(\mathrm{Fe}_{2} \mathrm{O}_{3}\right)$, which will then be used in the preparation of permanent magnet (strontium hexagonal hard ferrites).

Hard ferrite magnets are produced with iron oxide and strontium oxide. The raw materials are mixed and pre-sintered, to generate the magnetic phase. The resulting powder gets pressed together (wet or dry) either in a magnetic field (an-isotropic) or without a magnetic field (isotropic) and in the end sintered. Due to the low cost of the raw material, hard ferrite magnets are the cheapest magnet type out of the actual supply of magnets. Ferrites have a very good electrical isolation effect and are hard to demagnetize even in strong external magnetic fields ${ }^{[4]}$. To produce and maintain the magnetic field, a material should have both high residual induction (remanence) and high coercivity ${ }^{[3]}$. These materials, also known as oxide or ceramic magnets, are the most widely used magnets, especially for their low cost. Hexagonal ferrites are amongst the most widely used materials for permanent hard magnet applications $^{[4]}$.

\section{MATERIALS AND METHODS}

Different samples of steel industry byproduct collected from 2 different steel companies in Malaysia were used in this study. The hot-rolling mill scales and the cold-rolling waste were first milled using planetary ball mills for $24 \mathrm{~h}$. This was particularly effective in breaking up large pieces of the scales. The dried powder was then undergo magnetic separation and heat-treated at $400-600^{\circ} \mathrm{C}$. The phase formation of hematite $\left(\mathrm{Fe}_{2} \mathrm{O}_{3}\right)$ was confirmed by X-Ray Diffraction (XRD) analysis. The waste-derived $\mathrm{Fe}_{2} \mathrm{O}_{3}$ and strontium carbonate $\left(\mathrm{SrCO}_{3}\right)$ powders were wet-mixed and pre-sintered at $1150^{\circ} \mathrm{C}$ to produce strontium ferrite powders and to generate the magnetic phase. The mixing ratio of $\mathrm{Fe}_{2} \mathrm{O}_{3}-\mathrm{SrCO}_{3}$ was $\mathrm{x}$ to 1 where $\mathrm{x}$ was selected from 5.5-7.5 step 0.5. The powders were then blended and pressed into pellets. These pellets were sintered at $1200^{\circ} \mathrm{C}$ for $10 \mathrm{~h}$ (Fig. 1). The sintered samples were characterized by using an XRD analysis to confirm the formation of the strontium hard ferrite compound. The magnetic measurements carried out using Vibrating Sample Magnetometer (VSM). The magnetic properties; remanence and coercivity of the strontium hard ferrites magnets were then compared.

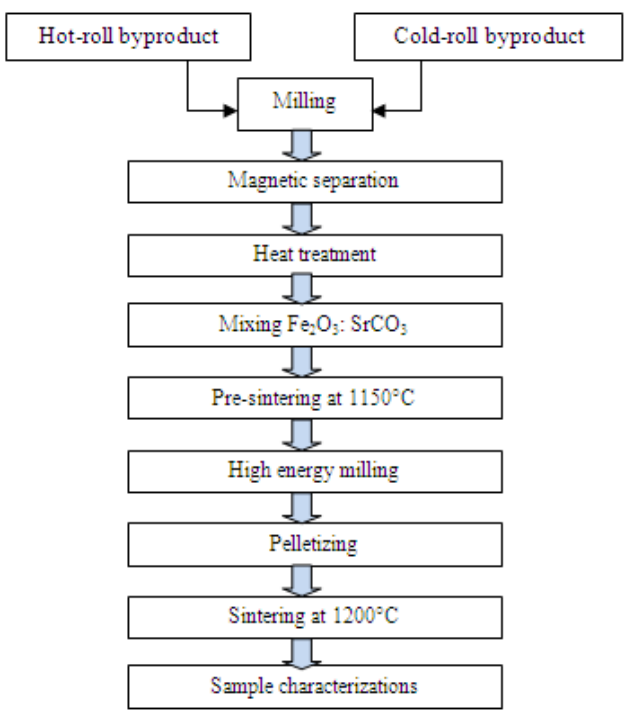

Fig. 1: Schematic diagram of strontium ferrite sintered magnets synthesis procedure

\section{RESULTS}

Steel industry waste is generally a rich iron source $(>70 \% \mathrm{Fe})$ and consists of three distinct layers of iron oxides; namely wuistite $(\mathrm{FeO})$, magnetite $\left(\mathrm{Fe}_{3} \mathrm{O}_{4}\right)$ and hematite $\left(\mathrm{Fe}_{2} \mathrm{O}_{3}\right)$. During the milling process in this study, the factory waste was grinded into ultra-fine particle and in the form of single-phase-particle. Using magnetic separation, we obtained defective $\mathrm{FeO}$ from the factory waste. This defective $\mathrm{FeO}$ was oxidized into useful $\mathrm{Fe}_{2} \mathrm{O}_{3}$. The following chemical equation illustrates the process:

$$
4 \mathrm{FeO}+\mathrm{O}_{2} \rightarrow 2 \mathrm{Fe}_{2} \mathrm{O}_{3}
$$

To confirm the presence of $\mathrm{Fe}_{2} \mathrm{O}_{3}$, the powders were scanned using $\mathrm{X}$-ray diffraction.

Figure 2 and 3 show the content of waste-derived hematite from two different steel factories (hot-roll and cold-roll waste), respectively. Both Fig. 2 and 3 show good agreement between the phases given by the wastederived hematite (hot-roll and cold-roll waste) and the standard phases of $\mathrm{Fe}_{2} \mathrm{O}_{3}$. The data above suggests the presence of $\mathrm{Fe}_{2} \mathrm{O}_{3}$ in our samples. However, X-ray diffraction analysis does not provide the quantitative information of the compound. Thus, we do not know the purity of hematite $\left(\mathrm{Fe}_{2} \mathrm{O}_{3}\right)$ obtained after the treatments above.

These waste-derived $\mathrm{Fe}_{2} \mathrm{O}_{3}$ were then used to prepare strontium hard ferrite $\mathrm{SrFe}_{12} \mathrm{O}_{19}$, through the chemical reaction below:

$$
\mathrm{SrCO}_{3}+6 \mathrm{Fe}_{2} \mathrm{O}_{3} \rightarrow \mathrm{SrFe}_{12} \mathrm{O}_{19}+\mathrm{CO}_{2}
$$


Again X-ray diffraction is used to confirm the presence of $\mathrm{SrFe}_{12} \mathrm{O}_{19}$.

Figure 4 and 5 show the $\mathrm{X}$-ray diffraction measurements on samples $\mathrm{SrFe}_{12} \mathrm{O}_{19}$ after several synthesis processes by using treated hot-roll and coldroll waste as starting materials. Both Fig. 3 and 4 show good agreement between the phases given by our samples (hot-roll and cold-roll) and the standard phases of $\mathrm{SrFe}_{12} \mathrm{O}_{19}$. It was confirmed that $\mathrm{SrFe}_{12} \mathrm{O}_{19}$ phase formed in the samples.

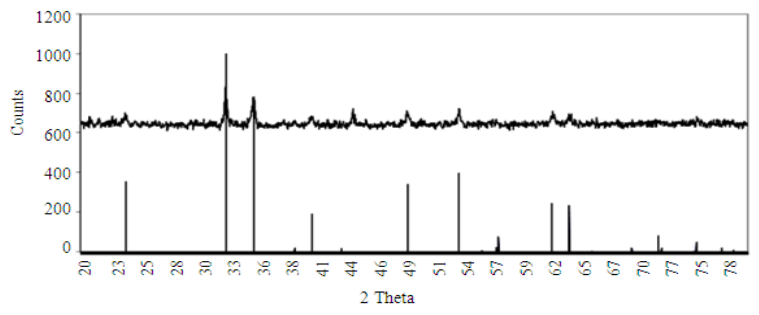

Fig. 2: Waste-derived hematite (hot-rolled)

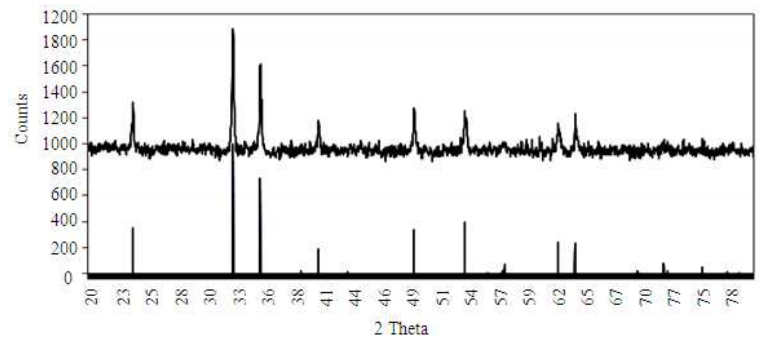

Fig. 3: Waste-derived hematite (cold-rolled)

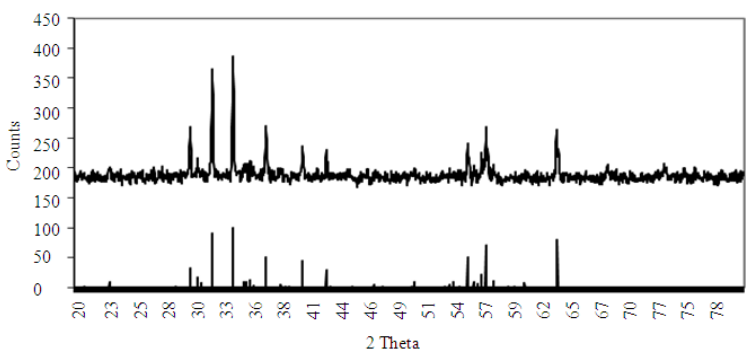

Fig. 4: Waste-derived strontium hard ferite (hot-rolled)

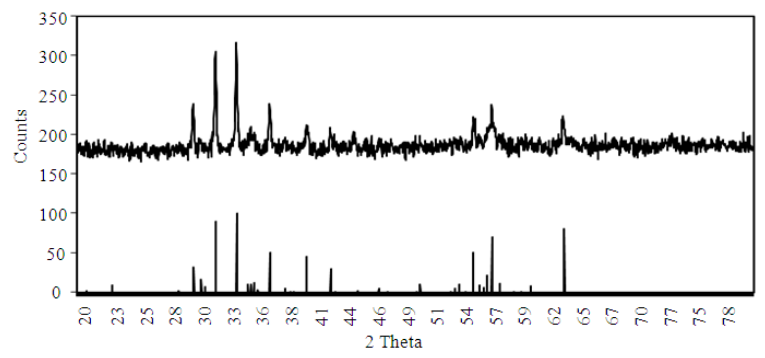

Fig. 5: Waste-derived strontium hard ferite (cold-rolled)
Good permanent magnets possess high remanence and coercivity. The magnetic properties of the samples in this study, i.e., the remanence and coercivity, were compared using VSM.

\section{DISCUSSION}

Figure 6 shows the remanence of the magnet produced using treated hot-roll and cold-roll waste as raw material with different mixing ratios. It is noted that generally the cold-roll waste produces higher remanence compared to the hot-roll waste. This is because the hematite derived from cold-roll waste is purer. With the significant amount of impurities in the hot-roll derived strontium hard ferrites, pinning effect occurs and thus prevents the alignment of the magnetic moments in the $\mathrm{SrFe}_{12} \mathrm{O}_{19}$ phase. As a results, the remanence of the hot-roll derived $\mathrm{SrFe}_{12} \mathrm{O}_{19}$ declined significantly. For the hot-roll derived $\mathrm{SrFe}_{12} \mathrm{O}_{19}$, the highest remanence seems to occur at the ratio $6: 1$, where the cold-roll derived $\mathrm{SrFe}_{12} \mathrm{O}_{19}$ achieved the maximum at the ratio 6.5:1. At this ratio, cold-rollderived $\mathrm{SrFe}_{12} \mathrm{O}_{19}$ phase dominant the sample. Magnetocrystalline anisotropic energy and the exchange energy (inter-molecular force) permit the alignment of the magnetic moment in the $\mathrm{SrFe}_{12} \mathrm{O}_{19}$ phase. The width of the domain walls change in the presence of magnetic field and thus enhance the remanence of the sample.

Figure 7 shows the coercivity of the magnet produced using treated hot-roll and cold-roll waste with different mixing ratios. It is noted that generally the cold-roll waste-derived $\mathrm{SrFe}_{12} \mathrm{O}_{19}$ produces lower coercivity compared to the hot-roll method. For the hot-roll method, the highest coercivity seems to occur at the ratio 6.5:1, while under the cold-roll method the maximum is achieved at the ratio 6:1. High coercivity implies the permanent magnet is hard to be demagnetized even in strong external magnetic fields.

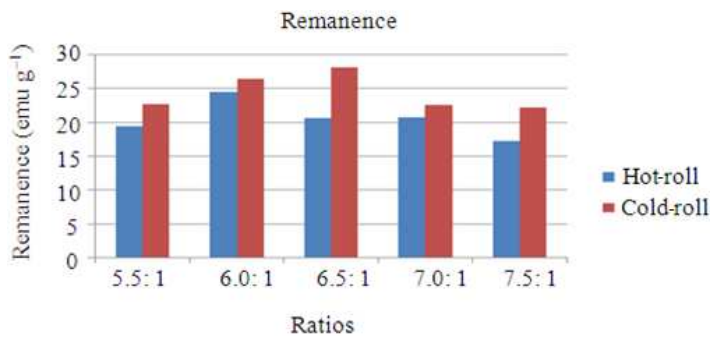

Fig. 6: Remanence of hot and cold-roll waste-derived strontium hard ferites 


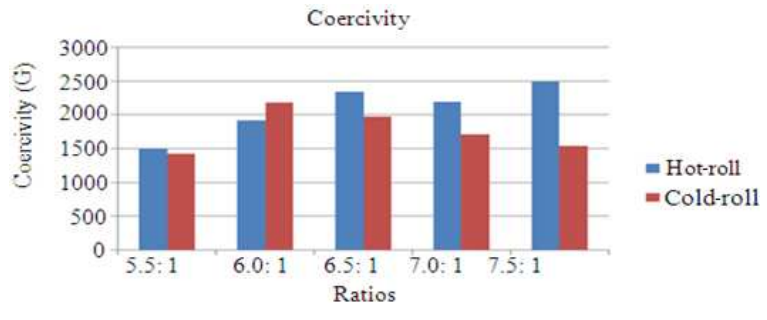

Fig. 7: Coercivity of hot and cold-roll waste-derived strontium hard ferites

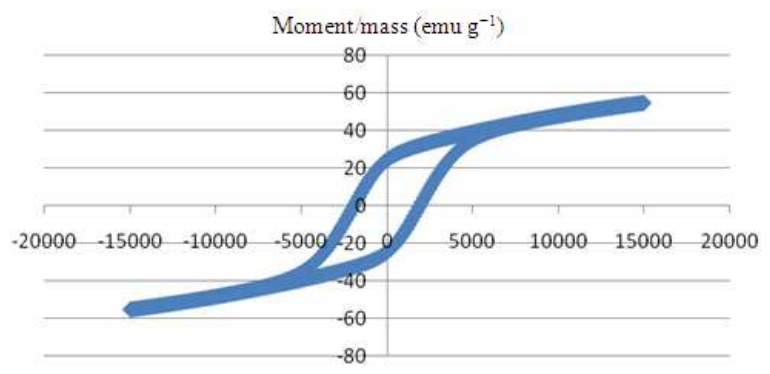

Fig. 8: Hysteresis-graph of hot-roll waste-derived strontium hard ferites (ratio 6:1)

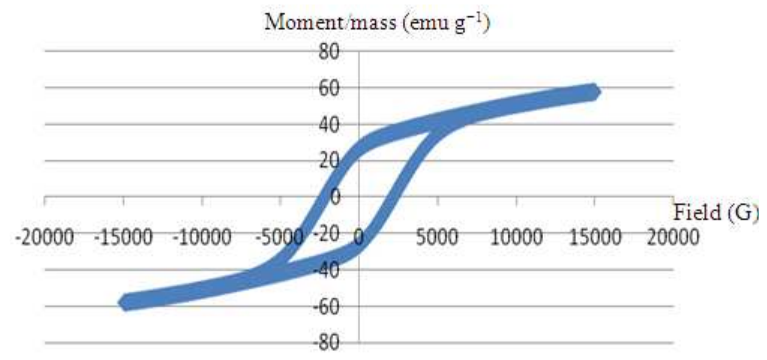

Fig. 9: Hysteresis-graph of cold-roll waste-derived strontium hard ferites (ratio 6.5:1)

It could be caused by the structure of the crystal (anisotropic) or the significant amount of impurities in the sample. Since the high coercivity value in the hotroll sample was follow by a decline in remanence, we may claim that the high value of coercivity in the sample (hot-roll) is caused by impurities and not the crystal structure.

The hyteresis-graphs of hot-roll and cold-roll waste-derived strontium hard ferrites with ratio 6.0:1 and 6.5:1 respectively is shown in Fig. 8 and 9.

\section{CONCLUSION}

The X-ray diffraction method revealed a good agreement between the phases given by steel industry waste-derived $\mathrm{Fe}_{2} \mathrm{O}_{3}$ (hot-roll and cold-roll) and the standard phases of $\mathrm{Fe}_{2} \mathrm{O}_{3}$. This method also confirm the fact that there is a good agreement between the phases given by steel industry waste-derived $\mathrm{SrFe}_{12} \mathrm{O}_{19}$ (hotroll and cold-roll) and the standard phases of $\mathrm{SrFe}_{12} \mathrm{O}_{19}$. To obtain the highest remanence and coercivity, the magnet are best mixed at a ratio $n: 1$, with a value of $n$ between 6 and 6.5.

\section{REFERENCES}

1. David, J., 1991. Introduction to Magnetism and Magnetic Material. 1st Edn., Chapman and Hall, ISBN: 041238640, pp: 229-323.

2. Parker, R.J., 1990. Advances in Permanent Magnetism. John Wiley and Sons, ISBN: 10: 0471822930 , pp: 337.

3. Ding, J., H. Yang and W.F. Miao, 1995. High coercivity $\mathrm{Ba}$ hexaferrite prepared by mechanical alloying. J. Alloys Comp., 221: 70-73. DOI: 10.1016/0925-8388(94)01402-7

4. Kwon, H.W. and J.W. Bae, 2004. Magnetic anisotropy of Sr-ferrite powder produced by mechanical alloying. J. Magnet. Magnet. Mater., 272-276:

E1823-E1825

DOI: 